\title{
Effects of dietary inclusion of probiotics, prebiotics and synbiotics on intestinal histological changes in challenged broiler chickens
}

\author{
H.H. Al-Baadani ${ }^{1}$, A.M. Abudabos ${ }^{1 \#}$, S.I. Al-Mufarrej ${ }^{1}$ \& M. Alzawqari ${ }^{2}$ \\ ${ }^{1}$ Department of Animal Production, College of Food and Agriculture Sciences, King Saud University, Saudi Arabia \\ ${ }^{2}$ Department of Animal Production, Faculty of Agriculture and Veterinary Medicine, Ibb University, Ibb, Yemen
}

(Received 2 November 2015; Accepted 23 March 2016; First published online 24 May 2016)

Copyright resides with the authors in terms of the Creative Commons Attribution 2.5 South African Licence.
See: http://creativecommons.org/licenses/by/2.5/za
Condition of use: The user may copy, distribute, transmit and adapt the work, but must recognise the authors and the South African
Journal of Animal Science.

\begin{abstract}
The present study aimed at evaluating the effects of probiotics, prebiotics and their combination on intestinal histological changes in broiler chickens challenged with Clostridium perfringens. Two hundred and forty newly hatched male broilers (Ross 308 ) were equally distributed into six treatments: negative control group: unsupplemented unchallenged birds; positive control group: unsupplemented challenged birds; neoxyval-fed group: $0.5 \mathrm{~g} / \mathrm{kg}$ diet (antibiotic) challenged birds; GalliPro-fed group: $0.6 \mathrm{~g} / \mathrm{kg}$ diet (probiotic), challenged birds; TechnoMos-fed group: $0.75 \mathrm{~g} / \mathrm{kg}$ diet (prebiotic), challenged birds; and synbiotic-fed group: birds challenged by C. Perfringens $\left(4 \times 10^{8} \mathrm{CFU} / \mathrm{mL}\right)$. At 35 days old, samples from the ileum and jejunum were collected for histological measurements (height, width and villus surface area), and histopathological changes were assessed. The results showed that the length and surface area of villi in the ileum and jejunum were lower in the positive control, whereas length and surface area of villi in the ileum and jejunum of all feed additive treatments were higher, compared with the positive control and antibiotics. Necrotic enteritis (NE) development was evident in the positive control group. Signs of necrosis of the mucosal membranes, haemorrhage and fibrosis with depletions of gut associated lymph follicle (GALF) in submucosal layer were very clear. Pathological changes improved in all feed additives, except for the antibiotics. These results indicated that alternatives to antibiotics could be used to improve the length and surface area of a villus and the health of the animal by suppressing $C$. perfringens.
\end{abstract}

Keywords: Broiler chickens, Clostridium perfringens, histomorphometric and histopathology changes

\#Corresponding author: alabudabos@gmail.com

\section{Introduction}

Clostridium perfringens is a common bacterium that causes necrotic enteritis (NE) in broiler chickens, which could lead to loss of performance (Abudabos et al., 2013). The intestines of birds suffering from NE contain large numbers of $C$. perfringens organisms, which could reach up to $10^{6}$ to $10^{8}$ colony-forming units $(\mathrm{CFU}) / \mathrm{g}$ of the intestinal contents, whereas in healthy broilers, the counts could range from 0 to $10^{5} \mathrm{CFU} / \mathrm{g}$ of the intestinal contents (Baba et al., 1997; Si et al., 2007). Among the major toxins, C. perfringens types B and $C$ produce beta and alpha toxin, while $C$. perfringens type A produces only alpha toxin. Alpha toxin has a major role in the occurrence of NE in poultry (Nauerby et al., 2003; Grimes et al., 2008). A subclinical disease associated with NE is characterized by damage to the intestinal mucosa, which decreases digestion and absorption, and reduces weight gain (Kaldhusdal et al., 2001). Microflora of the gastrointestinal tract of poultry play an important role in nutrient digestion, absorption and control of pathogens (Ashayerizadeh et al., 2014). However, proliferations of pathogenic bacteria in the gut often lead to intestinal inflammation, thus decreasing production rates and increasing mortality as well as risking the contamination of poultry products (Baurhoo et al., 2009). This resulted in antibiotics being used widely in the poultry industry to inhibit pathogens, prevent disease and act as growth promoters. However, in 2006 the European Union (EU) banned the use of growth-promoting antibiotics because of the increase in micro-organism resistance to antibiotics in both animals and humans (Hashemi \& Davoodi, 2010). Many researchers looked for alternatives to antibiotics that are safer for human health, such as prebiotics, probiotics and synbiotics (Mikelsaar \& Zilmer, 2009; Corcionivoschi et al., 2010).

Probiotics are live microbial feed supplements that affect the host animal beneficially by altering its intestinal microbial balance (Hassan et al., 2012). Prebiotics are non-digestible food ingredients that affect 
the host beneficially by selectively stimulating the growth and activity of one or a limited number of bacteria in the colon (Gibson et al., 2010). Synbiotics, on the other hand, are mixtures of probiotics and prebiotics (Yang et al., 2009). Prebiotics provide a great place for probiotics to thrive (Sekhon \& Jairath, 2010). Studies showed that the Bacillus subtilis strain improved intestinal microflora and inhibited pathogenic strains such as campylobacter and Clostridium species in broiler chickens (Mountzouris et al., 2007; Nayebpor et al., 2007; Ashayerizadeh et al., 2011; Abudabos et al., 2013). On the other hand, B. subtilis was shown to have a positive effect on the histomorphological and gut integrity of villi against $C$. perfringens-induced NE in broiler birds (Jayaraman et al., 2013).

Positive effects of prebiotics such as mannan-oligosaccharides (derived from yeast cell walls) have been reported in several studies (Klis et al., 2002). Oligosaccharides are believed to stimulate the growth of certain bacteria, especially Lactobacillus and Bifidobacteria species. Gibson \& Wang (1994) reported that fermentation products in the intestine could in part explain the inhibition of pathogenic bacteria such as $C$. perfringens by oligosaccharides. Therefore, these products might be promising alternatives to antibiotic growth promoters in poultry feeding (Samanya \& Yamauchi, 2002).

However, the results of previous studies on the effectiveness of eubiotic supplementation to poultry diets were inconsistent regarding the intestinal histological changes under challenge by $C$. perfringens. The purpose of this study was to differentiate between the effects of antibiotic, probiotic, prebiotic and synbiotic supplementation on intestinal histological changes in broiler chickens that were challenged with $C$. perfringens.

\section{Materials and Methods}

Two hundred and forty newly hatched chicks (Ross 308) were used in this experiment. The birds were obtained from a commercial hatchery (Al Bayad Farms Co., Riyadh, Saudi Arabia). The experimental period was from 1 to 35 days old. The chicks were reared in electrically heated cages, and divided into six treatment groups. The temperature was set at $33^{\circ} \mathrm{C}$ for the first week and gradually decreased to $22{ }^{\circ} \mathrm{C}$ at the end of the third week, where it remained constant until the end of the experiment. Feed and water were provided ad libitum and birds were maintained on a 24-hour light schedule. Birds were fed starter (0 - 14 days) and finisher (15 - 35 days) diets based on maize and soybean meals in mashed form. Dietary treatments were distributed randomly to each block according to Table 1.

Table 1 Dietary treatments for broiler chickens challenged with Clostridium perfringens

\begin{tabular}{|c|c|c|c|}
\hline Group & Treatment & Supplement & $\begin{array}{l}\text { C. perfringens } \\
\left(4 \times 10^{8} \mathrm{CFU} / \mathrm{mL}\right)^{1}\end{array}$ \\
\hline 1 & Negative control & No & No \\
\hline 2 & Positive control & No & Yes \\
\hline 3 & Antibiotic & Commercial Neoxyval $^{\circledR}(0.5 \mathrm{~g} / \mathrm{kg})^{1}$ & Yes \\
\hline 4 & Probiotic & GalliPro $^{\circledast}(0.6 \mathrm{~g} / \mathrm{kg})^{2}$ & Yes \\
\hline 5 & Prebiotic & TechnoMos $^{\circledR}(0.75 \mathrm{~g} / \mathrm{kg})^{3}$ & Yes \\
\hline 6 & Synbiotic & $\begin{array}{l}\text { Mixture of GalliPro }{ }^{\circledast}(0.6 \mathrm{~g} / \mathrm{kg}) \text { and } \\
\text { TechnoMos }^{\circledR}(0.75 \mathrm{~g} / \mathrm{kg})\end{array}$ & Yes \\
\hline
\end{tabular}

Group 1 contains 200 mg oxytetracycline and 200 mg neomycin (Sogeval Laboratory, France).

Group 2 consists of Bacillus subtilis, based direct fed microbial (DMF) (Brioche, Lone, Germany).

Group 3 is rich in MOS and $\beta-1,3$ glucanes and derived from the Saccharomyces cerevisiae cell membrane of the yeast (Brioche, Lone, Germany).

${ }^{1}$ according to Abudabos et al. (2013).

On days 15 and 17 , the chicks were gavaged with $1 \mathrm{~mL}$ cocktail containing $4 \times 10^{8} \mathrm{CFU} / \mathrm{mL} C$. perfringens, which was obtained commercially (MicroBiologics, Cloud, Minn, USA).

On day 35, the small intestines from eight birds per treatment were removed aseptically. The ileum (proximal to ileo-caecal junction) and jejunum (proximal to Meckel's diverticulum) were separated. A 2-cm samples were taken from both the ileum and jejunum for histology measurements without straining the intestinal wall. Samples were fixed in 10\% (vol/vol) phosphate-buffered formalin for at least 72 hours, after which they were dehydrated in graded alcohol, and embedded in paraffin. Sections of $5 \mu \mathrm{m}$ were cut from 
each sample by the microtome system and stained with haematoxylin and eosin according to the method described by Samanya \& Yamauchi (2002) and Hassan et al. (2012).

Measurements of villus height and width were based on at least six well-oriented villi per section per bird using an Ix71 Inverted Olympus Microscope (eyepiece: WH10x; objective lens: 4x) and a PC-based image analysis system (Olympus DP72 microscope digital camera; Olympus NV, Aartselaar, Belgium) with software analysis (cellSens digital imaging software for research application). Villus height and width data were used to calculate villus surface area $[2 \pi \times(\mathrm{W} / 2) \times \mathrm{L}]$, where $\mathrm{W}=$ villus width and $\mathrm{L}=$ villus length (Sohail et al., 2012).

Histopathological changes in the samples were examined microscopically (300 to 1200x). Lesions that are described include intestinal lesion scores; gut associated lymphoid follicles; intestinal structures (villus height and thickness) and intestinal crypts; goblet cells in villus enterocytes; necrosis of intestinal villus tips, inflammatory cells and desquamation of villus epithelial cells inside the intestinal lumen. Submucosal congestion and haemorrhage were observed in all samples according to the method described by Belih et al. (2015).

All data were analysed as a completely randomized block design using the general linear model of SAS (2008). The statistical differences between means were analysed with Duncan's multiple range test of the GLM procedure. Data were subjected to ANOVA with JMP software version 11, before being analysed with SAS (Leandro et al., 2011).

\section{Results and Discussion} Table 2.

The effects of dietary additives on intestinal histomorphology in broiler chickens are presented in

Table 2 Effects of dietary supplementation with antibiotic, probiotic, prebiotic and synbiotic on histomorphometric measurements of small intestine in broilers (35 days)

\begin{tabular}{|c|c|c|c|c|c|c|}
\hline \multirow[b]{2}{*}{ Treatments } & \multicolumn{3}{|c|}{ Ileum } & \multicolumn{3}{|c|}{ Jejunum } \\
\hline & $\begin{array}{c}\mathrm{L} \\
(\mu \mathrm{m})\end{array}$ & $\begin{array}{c}W \\
(\mu \mathrm{m})\end{array}$ & $\begin{array}{c}\mathrm{SA} \\
\left(\mathrm{mm}^{2}\right)\end{array}$ & $\begin{array}{c}\mathrm{L} \\
(\mu \mathrm{m})\end{array}$ & $\begin{array}{c}\mathbf{W} \\
(\mu \mathrm{m})\end{array}$ & $\begin{array}{c}\mathrm{SA} \\
\left(\mathrm{mm}^{2}\right)\end{array}$ \\
\hline Negative control & $423.65^{b}$ & $73.91^{b}$ & $0.094^{b}$ & $520.06^{c}$ & $66.33^{a}$ & $0.109^{d}$ \\
\hline Positive control & $353.10^{c}$ & $70.29^{b}$ & $0.076^{c}$ & $432.10^{d}$ & $67.75^{\mathrm{a}}$ & $0.092^{e}$ \\
\hline Antibiotic & $344.36^{c}$ & $69.46^{\mathrm{b}}$ & $0.075^{c}$ & $561.29^{c}$ & $58.26^{b}$ & $0.104^{d}$ \\
\hline Probiotic & $504.21^{a}$ & $79.58^{a b}$ & $0.128^{a}$ & $623.25^{b}$ & $65.12^{a}$ & $0.128^{c}$ \\
\hline Prebiotic & $527.94^{a}$ & $84.65^{\mathrm{a}}$ & $0.140^{a}$ & $643.89^{b}$ & $68.45^{\mathrm{a}}$ & $0.138^{b}$ \\
\hline Synbiotic & $452.28^{b}$ & $84.39^{a}$ & $0.124^{a}$ & $733.56^{a}$ & $68.74^{\mathrm{a}}$ & $0.158^{a}$ \\
\hline SEM & 15.024 & 3.742 & 0.006 & 11.103 & 1.357 & 0.004 \\
\hline$P$-value & $<.0001$ & 0.0027 & $<.0001$ & $<.0001$ & $<.0001$ & $<.0001$ \\
\hline
\end{tabular}

L: villus length; W: villus width; SA: surface area.

SEM: standard error of the mean.

${ }^{\mathrm{a}-\mathrm{e}}$ Means values within a column with different superscripts are significantly different $(P<0.05)$.

Ileum and jejunum villus length and surface area were lower $(P<0.05)$ in the positive control group compared with the negative control group. This might be due to $C$. perfringens, which caused necrotic inflammation in the intestinal wall (Kaldhusdal et al., 2001; Teo \& Tan, 2005), whereas villus width showed no differences in the positive control group compared with the negative control. Supplementations of probiotic, prebiotic and synbiotic groups increased the length and surface area of villi in the ileum and jejunum, compared with the positive control and antibiotic groups $(P<0.05)$. In addition, antibiotic supplementation increased $(P<0.05)$ the length and surface area of villi in the jejunum, compared with the positive control group, whereas the ileum was not affected. On the other hand, dietary supplementation with synbiotics increased $(P<0.05)$ the length and surface area of jejunum villi compared with all other groups. Synbiotic supplementation decreased ileum villus length compared with the probiotic and prebiotic groups $(P$ $<0.05)$. These findings are in line with the results of Samanya \& Yamauchi (2002), who reported that $B$. subtilis led to an increase in villus height in the small intestine. Abdel-Raheem et al. (2012) and Sen et al. 
(2012) reported that dietary supplementations of $B$. subtilis increased villus length in comparison with the dietary control. In a later study, $B$. subtilis was found to increase the length and surface area of villi when compared with the positive control group under challenge by $C$. perfringens (Jayaraman et al., 2013). Higher surface area in villi was reported as a result of MOS supplementation as prebiotic compared with the control group (Loddi et al., 2002). Oliveira et al. (2009) found that the addition of the antibiotic to broiler feed caused low villi height, which was explained by the suppressing effect of the antibiotic on beneficial bacteria in the gut, such as lactobacillus and bifidobacteria.

Jejunal villus width was not affected $(P>0.05)$ by dietary supplementation compared with the positive control group, except for the antibiotic group, which had lower width. lleal villus width for the prebiotic and synbiotic groups was higher than the positive control and antibiotic groups. Gunal et al. (2006) and Chichlowski et al. (2007) demonstrated that the villus width was not affected by probiotic and antibiotic flavomycin compared to the basal diet of broilers.

The results reported in this trial indicate that villus height is a direct representation of intestine function and health (Uni et al., 1995). This suggests that the villus function is activated after feeding dietary probiotics, prebiotics and synbiotics (Zhang et al., 2005). Also, the increased surface area reported in this trial as a result of probiotic, prebiotic and synbiotic supplementation may improve the absorption of nutrients (Caspary, 1992; Khambualai et al., 2010).

The results of the histopathological changes in the small intestine from various groups are presented in Figures 1 - 12). Birds that were fed on the unsupplemented diet and were not infected with $C$. perfringens (control negative group) showed normal intestinal coats, with a few goblet cells in villus enterocytes (Figure 1). The control positive group showed broad tips of the intestinal villi with a proliferation of enterocytes, together with heterophils infiltration and oedema in the lamina propria (Figure 2).

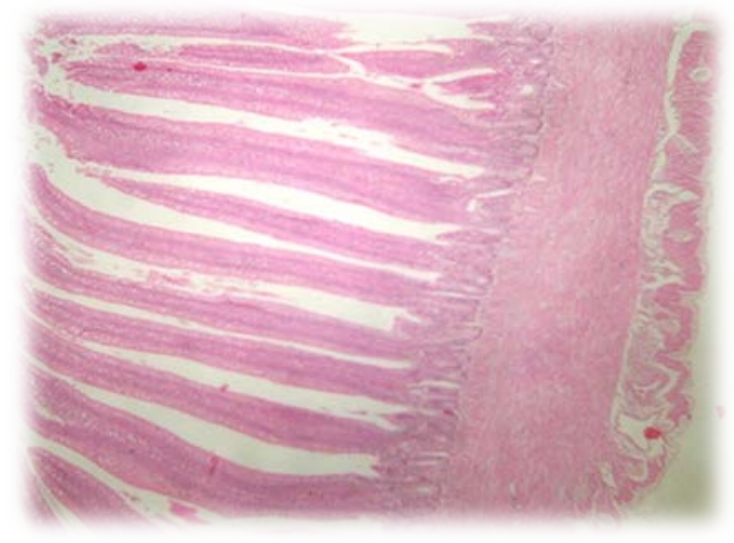

Figure 1 Intestine of chicken (negative control group) showing normal intestinal coats structures (villus height and width) and intestinal crypts. A few goblet cells in villus enterocytes. $H \& E(X 300)$.

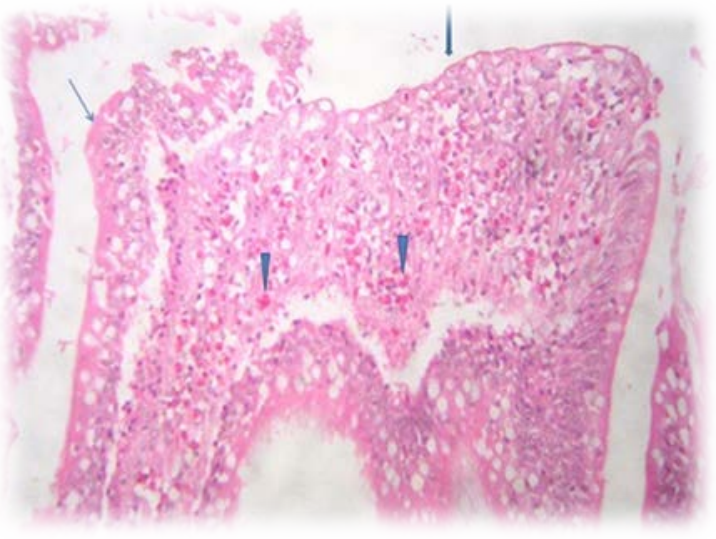

Figure 2 Intestine of chicken (positive control group) showing broad ulcerated villus surface (thick arrow), thickened lamina propria infiltrated by heterophils (arrowhead) and intense desquamation of villus epithelial cells (thin arrow). H\&E (X 1200).

The results of the histopathological changes in the small intestine from birds that fed on the unsupplemented diet and were infected with C. perfringens (positive group) are presented in Figures 3 and 4. Some villi tips were partially desquamated with the presence of sheets inside their lumen, metaplasia of goblet cells and submucosa containing some extravaseted erythrocytes (haemorrhage), while the gut associated lymph follicle (GALF) revealed a reduction of leukocytes cells (lymphoid depletion). In some cases, disorganized villus height and width were reported. Sticking of eosinophilic mucous containing some inflammatory cells in the intestinal mucosa is clear in the positive group. In some cases, submucosal fibroblast proliferation (fibrosis) was observed and tunica muscular appeared oedematous (Figures 3 and 4). 


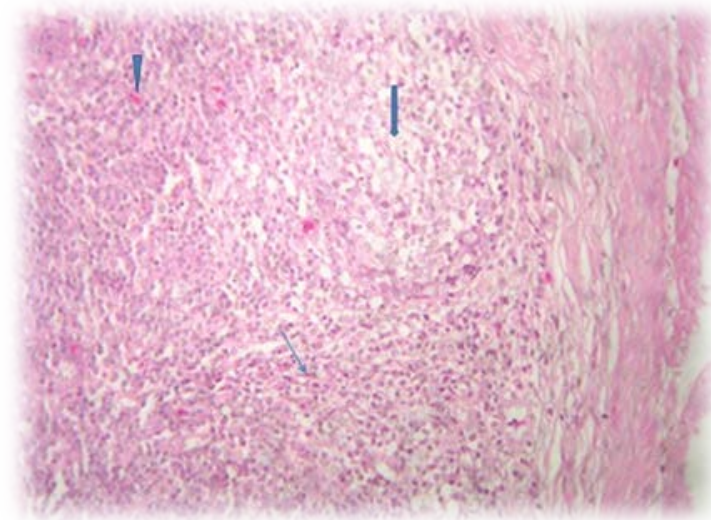

Figure 3 Intestine of chicken (positive control group) showing sever depletions of gut associated lymphoid follicles (thick arrow), a few extravasated erythrocytes (arrowhead) and spindle cells proliferation (thin arrow). H\&E (X 1200)

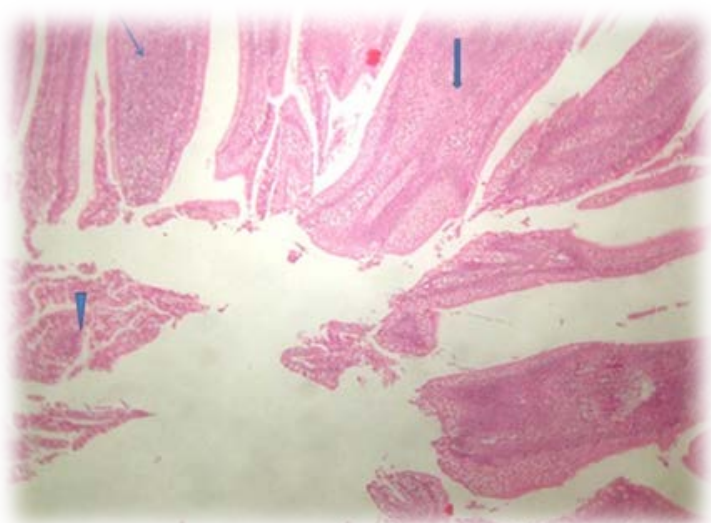

Figure 4 Intestine of chicken (positive control group) showing disorganized villi with fusion in some villus tips (thick arrow), lumens contain desquamated epithelial cells, and sheet with some inflammatory cells (arrowhead) and thickened mucosal lamina propria by inflammatory cells (thin arrow). H\&E (X 300)

Dietary supplementation with the antibiotic showed partial necrotic enteritis in the inner third of the intestinal villi, characterized by loss of tissue architecture and accumulation of tissue debris, mucus and desquamated intestinal sheets in the lumens (Figures 5 and 6). Height and width of intestinal villi were more regular than the positive control group without inflammatory cells. Epithelial proliferation in the villi and intestinal crypts, accompanied by goblet cell metaplasia or partial desquamations, submucosal congestion, haemorrhage of GALF (Figure 7) were also observed in the antibiotic group.

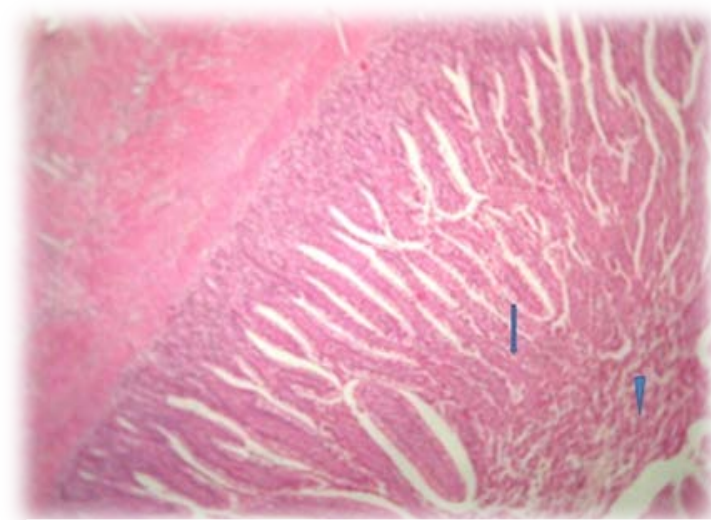

Figure 5 Intestine of chicken (antibiotic group) showing partial necrosis of some villi tips (thick arrow), inflammatory exudate inside the intestinal lumen (arrowhead). H\&E (X 300)

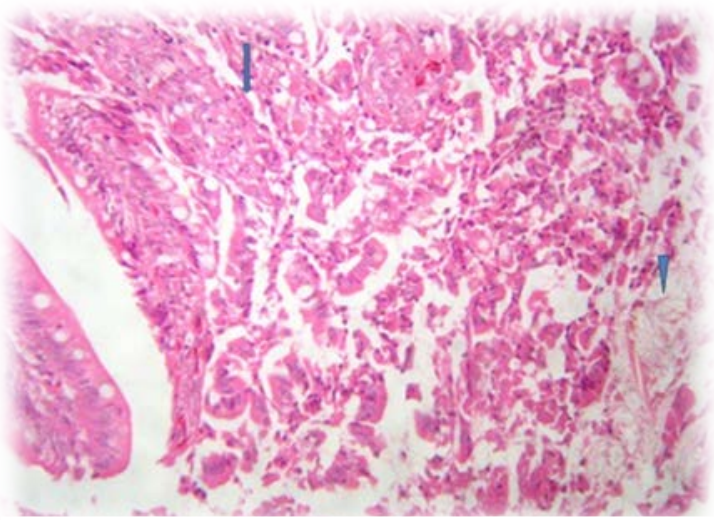

Figure 6 High power resolution of the previous figures to show necrotic intestinal villus tips (arrow) and presence of mucous, desquamated intestinal sheet within the intestinal lumen (arrowhead). H\&E (X 400). 


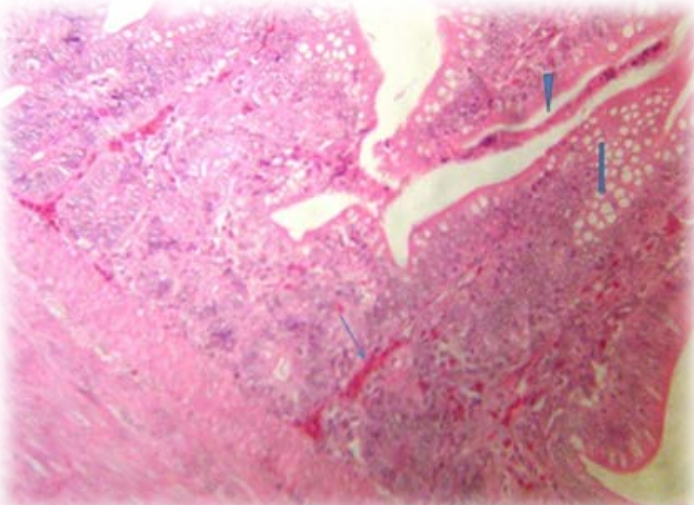

Figure 7 Intestine of chicken (antibiotic group) showing proliferative villus epithelium and gland, with goblet cells metaplasia (arrow), partial necrosis of some villus epithelium (arrowhead), together with submucosal congestion and hemorrhage (thin arrow). H\&E (X 300).

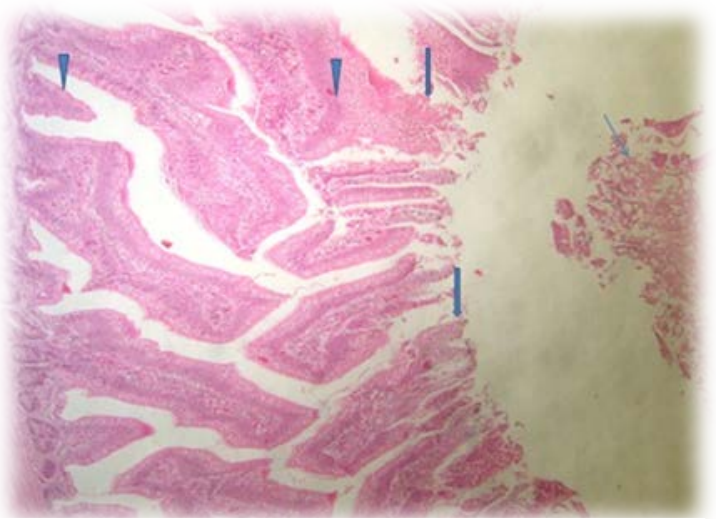

Figure 8 Intestine of chicken (probiotic group) showing separation and coagulated necrosis of villus superficial tips (arrow), regenerative attempts from the lower villus epithelium and intestinal crypts (arrowhead) and a few inflammation cells and desquamation epithelial in the intestinal lumen (thin arrow). H\&E ( $X$ 300).

The probiotic group had normal appearance in villi height and width. However, partial coagulated necrosis, separation of some villi tips, desquamated epithelial sheet and a few inflammatory cells were observed in the lumen. Regenerative attempts were also detected in the deep structure of villus epithelium and crypts (Figures 8 and 9).

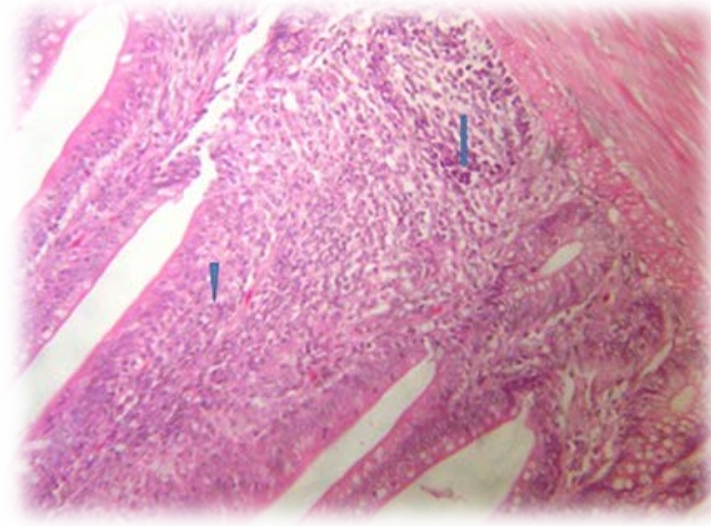

Figure 9 Intestine of chicken (probiotic group) showing hyper plastic lymphoid tissue (arrow) and broad (thickened) intestinal villi (arrowhead). H\&E (X 300).

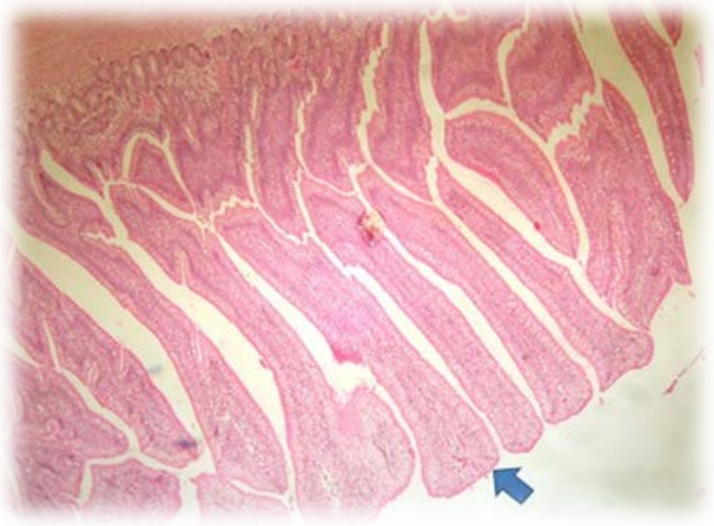

Figure 10 intestine of chicken (Prebiotic group) showing broad and thickened villus tips in most intestinal villi and an increase in absorptive surfaces without exudate in the lumen. $H \& E$ ( $X$ 300).

The small intestine of the prebiotic supplemented group exhibited broad and thick tips in most intestinal villi with an increase in the intestinal width and the absorptive surfaces without exudate inside the lumen. However, some villi revealed goblet cell proliferations (Figure 10).

The synbiotic group showed tall and thin intestinal villi, lined by hyperplastic villus epithelium containing numerous goblet cells, as well as a few necrotic tissues, and desquamated epithelium on the surface of the intestinal villi (Figures 11 and 12). 


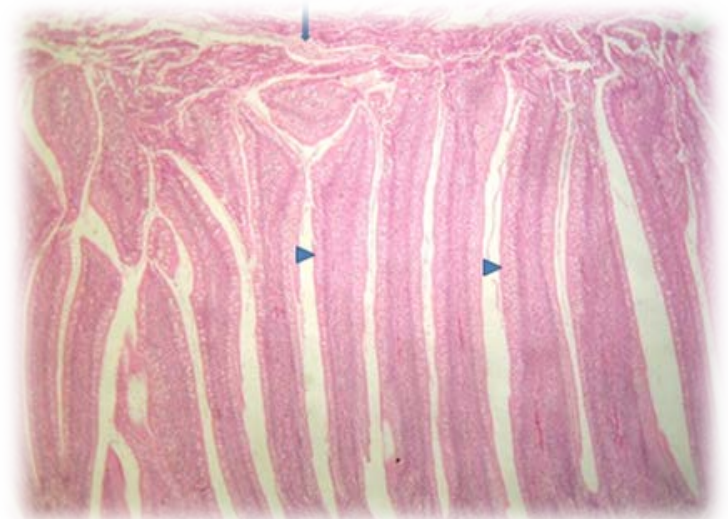

Figure 11 Intestine of chicken (mixture group) showing tall and thin intestinal villi lined by hyperplastic villus epithelium containing numerous goblet cells (arrowhead), beside a few necrotic tissue (arrow), and desquamated epithelium on the surface of some intestinal villi (thick arrow). H\&E (X 300).

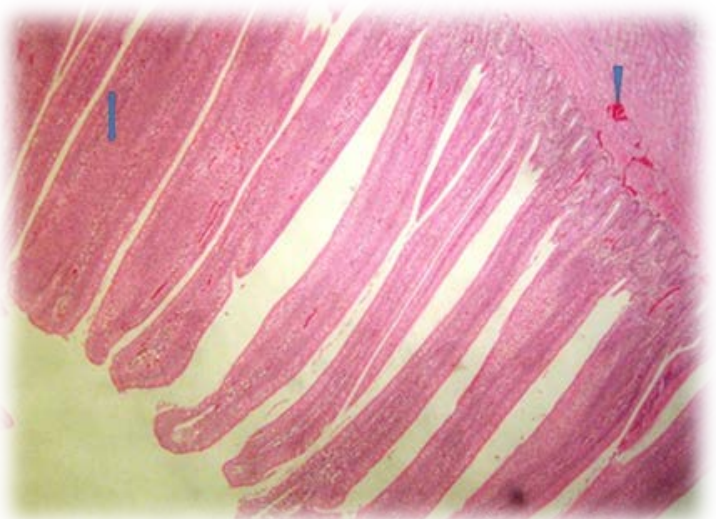

Figure 12 Intestine of chicken (mixture group) showing organized and apparently normal villi with fusion villi (arrow), and congestion of the muscular blood vessels (arrowhead). H\&E (X 300).

The lesion score in the positive control group (infected with C. perfringens, without supplementation) developed NE. Compared with the negative control group (uninfected), disorganized villus height and width, sticking of eosinophilic mucous containing some inflammatory cells on the intestinal mucosa and necrosis of the mucous membranes were observed, as well as haemorrhage and fibrosis with depletions of GALF of leukocytes cells in the submucosal. Lymphoid depletion could indicate a negative effect on the immune status of the birds since they are unable to produce enough antibodies as a result of NE. This result is in agreement with Gazdzinski \& Julian (1992), who reported that turkeys infected with Clostridial enteritis were observed to have lymphoid depression in the bursa of Fabricius, due to clostridial toxin. In addition, the broad tips of the intestinal villi with the proliferation of enterocytes, together with heterophil infiltration and oedema in the lamina propria, were consistent with the results by Olkowski et al. (2006). The results of this study are consistent with those of Jayaraman et al. (2013), who reported that birds infected with C. perfringens showed markedly thickened mucosa, haemorrhages and intestinal ballooning. Asaoka et al. (2004), Yang et al. (2009) and Khambualai et al. (2010) found that NE was characterized by extensive necrosis in the mucosa and haemorrhages, as well as inflammatory cell infiltration in birds infected with $C$. perfringens. This is also evident from the ability of the groups that were supplemented with prebiotics, probiotics and synbiotics to control the NE. Similar results showed that dietary supplementation with probiotics and prebiotics improved the morphometric histological status and absorption surface, and decreased pathogenic bacteria (Awad et al., 2009). According to Kizerwetter-Swida \& Binek (2008), dietary supplementation with probiotics decreased $C$. perfringens counts in the small intestine of turkeys. Hassan et al. (2012) showed that the use of probiotics and prebiotics led to inhibition of pathogenic bacteria, which destroy the intestinal wall with toxins. This can be attributed to the production of anticlostridial factors by $B$. subtilis (Teo \& Tan, 2005) and that this prebiotic inhibits $C$. perfringens-induced NE by competitive exclusion that improves intestinal health (Brennan et al., 2013). The synbiotic group showed synergies between the probiotics and prebiotics. It is hypothesized that the increase in the number of beneficial bacteria led to improved intestinal health of the bird. These results are in agreement with those reported by Awad et al. (2009). Many researchers have reported that probiotics and synbiotics enhance the performance of broilers by improving the intestinal morphology and microbial balance associated with suppressing pathogens and increasing the nutrient digestibility in the small intestine (Li et al., 2007; Ashayerizadeh et al., 2009). Birds that are experiencing chronic intestinal enteritis are in a constant mode of inflammation and recovery (Star et al., 2010). This may lead to changes in the villi and crypts as a result of the renewal of the villi as a response to inflammation from pathogens or their toxins. The effect of inflammation due to pathogens or their toxins may lead to poor nutrient absorption and lower performance in birds (Xu et al., 2003).

\section{Conclusions}

The result of this study showed that the worst histomorphometrical and histopathological measurements were associated with the positive control group. Villus surface area increased in the small intestine because of probiotic, prebiotic and synbiotic supplementation, which may improve the absorption of 
nutrients and could be an indication of satisfactory intestinal status. Birds infected with C. perfringens and offered no supplementation developed markedly thickened mucosa, haemorrhages and intestinal ballooning. However, the groups that were offered prebiotics, probiotics and synbiotics were able to control the NE.

\section{Acknowledgements}

The authors would like to extend their sincere appreciation to the Deanship of Scientific Research, Research Centre, at King Saud University, for funding this research.

\section{Authors' Contributions}

$\mathrm{AM}$ and $\mathrm{HH}$ designed, conducted the growth trial and collected the samples from the birds. $\mathrm{M}$ did the histological slides. $\mathrm{AM}$ and $\mathrm{HH}$ interpreted the slides and prepared the figures. $\mathrm{AM}, \mathrm{HH}$ and $\mathrm{SI}$ did the statistical analyses. AM and $\mathrm{HH}$ wrote the manuscript and submitted the manuscript.

\section{Conflict of interest declaration}

There is no conflict of interest.

\section{References}

Abdel-Raheem, S.M., Abd-Allah, S.M. \& Hassanein, K.M., 2012. The effects of prebiotic, probiotic and synbiotic supplementation on intestinal microbial ecology and histomorphology of broiler chickens. Int. J. Agro. Vet. Med. Sci. 6, 277-289.

Abudabos, A.M., Alyemni, A.H. \& Al Marshad, M., 2013. Bacillus subtilis PB6 based-probiotic (CloSTAT ${ }^{\text {TM}}$ ) improves intestinal morphological and microbiological status of broiler chickens under clostridium perfringens challenge. Int. J. Agric. Biol. 15, 978-982.

Asaoka, Y., Yanai, T., Hirayama, H., Une, Y., Saito, E., Sakai, H., Goryo, M., Fukushi, H. \& Masegi, T., 2004. Fatal necrotic enteritis associated with Clostridium perfringens in wild crows (Corvus macrorhynchos). Avian Patho. 33, $19-24$.

Ashayerizadeh, A., Dabiri, N., Ashayerizadeh, O., Mirzadeh, K.H., Roshanfekr, H. \& Mamooee, M., 2009. Effect of dietary antibiotic, probiotic and prebiotic as growth promoters, on growth performance, carcass characteristics and hematological indices of broiler chickens. Pakis. J. Biol. Sci. 12, 52-57.

Ashayerizadeh, A., Dabiri, N., Mirzadeh K. \& Ghorbani, M., 2011. Effect of dietary supplementation of probiotic and prebiotic on growth indices and serum biochemical parameters of broiler chickens. J. Cell Anim. Biol. 5, 152-156.

Ashayerizadeh, O., Dastar, B., Samadi, F., Khomeiri, M., Yamchi, A. \& Zerehdaran, S., 2014. Comparison between the effects of two multi-strain probiotics and antibiotic on growth performance, carcass characteristics, gastrointestinal microbial population and serum biochemical values of broiler chickens. Sci. J. Anim. Sci. 3, 110-119.

Awad, W., Ghareeb, K., Abdel-Raheem, S. \& Böhm, J., 2009. Effects of dietary inclusion of probiotic and synbiotic on growth performance, organ weights, and intestinal histomorphology of broiler chickens. Poult. Sci. 88, 49-56.

Baba, E., Ikemoto, T., Fukata, T., Sasai, K., Arakawa, A. \& McDougald, L., 1997. Clostridial population and the intestinal lesions in chickens infected with Clostridium perfringens and Eimeria necatrix. Vet. Microbiol. 54, 301-308.

Baurhoo, B., Ferket, P. \& Zhao, X., 2009. Effects of diets containing different concentrations of mannanoligosaccharide or antibiotics on growth performance, intestinal development, cecal and litter microbial populations, and carcass parameters of broilers. Poult. Sci. 88, 2262-2272.

Belih, S.S., Labib, Z.M. \& Ragab, A.M., 2015. Role of Saltose probiotic for the control of the experimental infection of the Clostridium perfringens and the Coccidia in chickens. AJVS. 46, 20-41.

Brennan, K., Graugnard, D., Xiao, R., Spry, M., Pierce, J., Lumpkins, B. \& Mathis, G., 2013. Comparison of gene expression profiles of the jejunum of broilers supplemented with a yeast cell wall-derived mannan oligosaccharide versus bacitractin methylene disalicylate. Br. Poult. Sci. 54, 238-246.

Caspary, W.F., 1992. Physiology and pathophysiology of intestinal absorption. Am. J. Clin. Nutr. 55, 299-308.

Chichlowski, M., Croom, J., McBride, B., Daniel, L., Davis, G. \& Koci, M., 2007. Direct-fed microbial PrimaLac and salinomycin modulate whole-body and intestinal oxygen consumption and intestinal mucosal cytokine production in the broiler chick. Poult. Sci. 86, 1100-1106.

Corcionivoschi, N., Drinceanu, D., Pop, I.M., Stack, D., Ştef, L., Julean, C. \& Bourke, B., 2010. The effect of probiotics on animal health. Anim. Sci. Biotechnol. 43, 35-41.

Gazdzinski, P. \& Julian, R., 1992. Necrotic enteritis in turkeys. Avian Dis. 36, 792-798.

Gibson, G. \& Wang, X., 1994. Regulatory effects of bifidobacteria on the growth of other colonic bacteria. J. Appl. Bacteriol. 77, 412-420.

Gibson, G.R., Scott, K.P., Rastall, R.A., Tuohy, K.M., Hotchkiss, A., Dubert-Ferrandon, A., Gareau, M., Murphy, E.F., Saulnier, D. \& Loh, G., 2010. Dietary prebiotics: current status and new definition. Food Sci. Technol. Bull. Funct. Foods 7, 1-19.

Grimes, J.L., Rahimi, S., Oviedo, E., Sheldon, B.W. \& Santos, F.B.O., 2008. Effects of a direct-fed microbial (Primalac) on turkey poult performance and susceptibility to oral salmonella challenge. Poult. Sci. 87, 1464-1470.

Gunal, M., Yayli, G., Kaya, O., Karahan, N. \& Sulak, O., 2006. The effects of antibiotic growth promoter, probiotic or organic acid supplementation on performance, intestinal microflora and tissue of broilers. Int. J. Poult. Sci. 5, 149-155.

Hashemi, S. \& Davoodi, H., 2010. Phytogenics as new class of feed additive in poultry industry. J. Anim. Vet. Adv. 9, 2295-2304. 
Hassan, E.R., Zeinab, K.M.K.M.E., Girh, M.A. \& Mekky, H.M., 2012. Comparative studies between the effects of antibiotic (oxytetracycline); probiotic and acidifier on E. coli infection and immune response in broiler chickens. J. Amer. Sci. 8, 795-801.

Jayaraman, S., Thangavel, G., Kurian, H., Mani, R., Mukkalil, R. \& Chirakkal, H., 2013. Bacillus subtilis PB6 improves intestinal health of broiler chickens challenged with Clostridium perfringens-induced necrotic enteritis. Poult. Sci. 92, 370-374.

Kaldhusdal, M., Schneitz, C., Hofshagen, M. \& Skjerve, E., 2001. Reduced incidence of Clostridium perfringensassociated lesions and improved performance in broiler chickens treated with normal intestinal bacteria from adult fowl. Avian Dis. 45, 149-156.

Khambualai, O., Yamauchi, K.-e., Ruttanavut, J., Incharoen, T. \& Kashimura, J., 2010. Effect of sugar cane extract, commercial probiotic and their mixture on growth performance and intestinal histology in broiler chickens. Am. J. Anim. Vet. Sci. 5, 132-138.

Kizerwetter-Swida, M. \& Binek, M., 2009. Protective effect of potentially probiotic Lactobacillus strain on infection with pathogenic bacteria in chickens. Pol. J. Vet. Sci. 12, 15-20.

Klis, F.M., Mol, P., Hellingwerf, K. \& Brul, S., 2002. Dynamics of cell wall structure in Saccharomyces cerevisiae. Fems Microbial. Rev. 26, 239-256.

Leandro, N., Ali, R., Koci, M., Moraes, V., Malheiros, R., Wineland, M. \& Oviedo-Rondón, E., 2011. Effects of broiler breeder genetic, diet type, and feeding program on maternal antibody transfer and development of lymphoid tissues in chicken progeny. J. Appl. Poult. Res. 20, 474-484.

Li, X., Piao, X., Kim, S., Liu, P., Wang, L., Shen, Y., Jung, S. \& Lee, H., 2007. Effects of chito-oligosaccharide supplementation on performance, nutrient digestibility, and serum composition in broiler chickens. Poult. Sci. 86, $1107-1114$

Loddi, M., Nakaghi, L., Edens, F., Tucci, F., Hannas, M., Moraes, V. \& Ariki, J., 2002. Mannanoligosaccharide and organic acids on intestinal morphology integrity of broilers evaluated by scanning electron microscopy. In: Proc. 11th European Poult. Sci. Conf., Bremen, Germany. Sept. 6-10. Page 121.

Mikelsaar, M. \& Zilmer, M., 2009. Lactobacillus fermentum ME-3-an antimicrobial and antioxidative probiotic. Microb. Ecol. Health Dis. 21, 1-27.

Mountzouris, K., Tsirtsikos, P., Kalamara, E., Nitsch, S., Schatzmayr, G. \& Fegeros, K., 2007. Evaluation of the efficacy of a probiotic containing Lactobacillus, Bifidobacterium, Enterococcus, and Pediococcus strains in promoting broiler performance and modulating cecal microflora composition and metabolic activities. Poult. Sci. 86, 309-317.

Nauerby, B., Pedersen, K. \& Madsen, M., 2003. Analysis by pulsed-field gel electrophoresis of the genetic diversity among Clostridium perfringens isolates from chickens. Vet. Microbiol. 94, 257-266.

Nayebpor, M., Farhomand, P. \& Hashemi, A., 2007. Effects of different levels of direct fed microbial (Primalac) on growth performance and humoral immune response in broiler chickens. J. Anim. Vet. Adv. 6, 1308-1313.

Oliveira, R.P., Florence, A.C., Silva, R.C., Perego, P., Converti, A., Gioielli, L.A. \& Oliveira, M.N., 2009. Effect of different prebiotics on the fermentation kinetics, probiotic survival and fatty acids profiles in nonfat symbiotic fermented milk. Int. J. Food Microbiol. 128, 467-472.

Olkowski, A., Wojnarowicz, C., Chirino-Trejo, M. \& Drew, M., 2006. Responses of broiler chickens orally challenged with Clostridium perfringens isolated from field cases of necrotic enteritis. Res. Vet. Sci. 81, 99-108.

Samanya, M. \& Yamauchi, K., 2002. Histological alterations of intestinal villi in chickens fed dried Bacillus subtilis var. natto. Comp. Biochem. Physiol. 133, 95-104.

SAS, 2008. Statistical Analysis Systems Users Guide: Statistics. SAS Institute Inc., Cary, NC., USA.

Sekhon, B.S. \& Jairath, S., 2010. Prebiotics, probiotics and synbiotics: An overview. J. Pharm. Educ. Res. 1, 13-36.

Sen, S., Ingale, S., Kim, Y., Kim, J., Kim, K., Lohakare, J., Kim, E., Kim, H., Ryu, M. \& Kwon, I., 2012. Effect of supplementation of Bacillus subtilis LS 1-2 to broiler diets on growth performance, nutrient retention, caecal microbiology and small intestinal morphology. Res. Vet. Sci. 93, 264-268.

Si, W., Gong, J., Han, Y., Yu, H., Brennan, J., Zhou, H. \& Chen, S., 2007. Quantification of cell proliferation and alphatoxin gene expression of Clostridium perfringens in the development of necrotic enteritis in broiler chickens. Appl. Environ. Microbiol. 73, 7110-7113.

Sohail, M., Hume, M., Byrd, J., Nisbet, D., Ijaz, A., Sohail, A., Shabbir, M. \& Rehman, H., 2012. Effect of supplementation of prebiotic mannan-oligosaccharides and probiotic mixture on growth performance of broilers subjected to chronic heat stress. Poult. Sci. 91, 2235-2240.

Star, L., Bruijn, N. \& Rovers, M., 2010. Dietary beta glucans to fight chronic enteritis. World Polit. 25, 14-16.

Teo, A.Y.L. \& Tan, H.-M., 2005. Inhibition of Clostridium perfringens by a novel strain of Bacillus subtilis isolated from the gastrointestinal tracts of healthy chickens. Appl. Environ. Microbiol. 71, 4185-4190.

Uni, Z., Noy, Y. \& Sklan, D., 1995. Posthatch changes in morphology and function of the small intestines in heavy-and light-strain chicks. Poult. Sci. 74, 1622-1629.

Xu, Z., Hu, C., Xia, M., Zhan, X. \& Wang, M., 2003. Effects of dietary fructooligosaccharide on digestive enzyme activities, intestinal microflora and morphology of male broilers. Poult. Sci. 82, 1030-1036.

Yang, Y., lji, P. \& Choct, M., 2009. Dietary modulation of gut microflora in broiler chickens: A review of the role of six kinds of alternatives to in-feed antibiotics. World's Poult. Sci. J. 65, 97-114.

Zhang, A., Lee, B., Lee, S., Lee, K., An, G., Song, K. \& Lee, C., 2005. Effects of yeast (Saccharomyces cerevisiae) cell components on growth performance, meat quality, and ileal mucosa development of broiler chicks. Poult. Sci. 84, 1015-1021. 